"Do geopolitical tensions instigate mindless following in stock markets? An empirical enquiry into the indices of CNX Nifty HFT"

\begin{tabular}{|c|c|c|}
\hline AUTHORS & \multicolumn{2}{|l|}{$\begin{array}{l}\text { Krishna T. A. } \\
\text { Suresha B. (iD) }\end{array}$} \\
\hline ARTICLE INFO & \multicolumn{2}{|c|}{$\begin{array}{l}\text { Krishna T. A. and Suresha B. (2021). Do geopolitical tensions instigate mindless } \\
\text { following in stock markets? An empirical enquiry into the indices of CNX Nifty } \\
\text { HFT. Investment Management and Financial Innovations, 18(2), 335-349. } \\
\text { doi:10.21511/imfi.18(2).2021.27 }\end{array}$} \\
\hline DOI & \multicolumn{2}{|c|}{ http://dx.doi.org/10.21511/imfi.18(2).2021.27 } \\
\hline RELEASED ON & \multicolumn{2}{|l|}{ Thursday, 24 June 2021} \\
\hline RECEIVED ON & \multicolumn{2}{|l|}{ Sunday, 30 May 2021} \\
\hline \multirow[t]{2}{*}{ ACCEPTED ON } & \multicolumn{2}{|l|}{ Wednesday, 23 June 2021} \\
\hline & \multicolumn{2}{|l|}{$(\infty c)$ EY } \\
\hline LICENSE & \multicolumn{2}{|c|}{$\begin{array}{l}\text { This work is licensed under a Creative Commons Attribution } 4.0 \text { International } \\
\text { License }\end{array}$} \\
\hline JOURNAL & \multicolumn{2}{|c|}{ "Investment Management and Financial Innovations" } \\
\hline ISSN PRINT & \multicolumn{2}{|l|}{$1810-4967$} \\
\hline ISSN ONLINE & \multicolumn{2}{|l|}{$1812-9358$} \\
\hline PUBLISHER & \multicolumn{2}{|c|}{ LLC "Consulting Publishing Company "Business Perspectives" } \\
\hline FOUNDER & \multicolumn{2}{|c|}{ LLC “Consulting Publishing Company "Business Perspectives" } \\
\hline & & 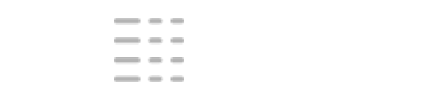 \\
\hline NUMBER OF REFERENCES & NUMBER OF FIGURES & NUMBER OF TABLES \\
\hline 27 & 6 & 5 \\
\hline
\end{tabular}

(C) The author(s) 2021. This publication is an open access article. 


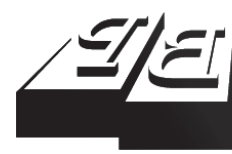

BUSINESS PERSPECTIVES

(2)

LLC "CPC "Business Perspectives" Hryhorii Skovoroda lane, 10, Sumy, 40022, Ukraine www.businessperspectives.org
Received on: $30^{\text {th }}$ of May, 2021 Accepted on: $23^{\text {rd }}$ of June, 2021 Published on: $24^{\text {th }}$ of June, 2021

(c) Krishna T. A., Suresha B., 2021

Krishna T. A., Doctoral Student, School of Business and Management, CHRIST (Deemed to be University), Bangalore, India.

Suresha B., Associate Professor, School of Business and Management, CHRIST (Deemed to be University), Bangalore, India.

\title{
DO GEOPOLITICAL TENSIONS INSTIGATE MINDLESS FOLLOWING IN STOCK MARKETS? AN EMPIRICAL ENQUIRY INTO THE INDICES OF CNX NIFTY HFT
}

\begin{abstract}
Geopolitical tensions between nations play a crucial role in triggering volatility and affecting the investors' behavior in stock markets. This empirical work attempts to detect the traces of herding and bubble embedded in the Indian stock indices of CNX Nifty 50 and CNX Nifty 100 (both in High-Frequency Trading domains) during the latest events of geopolitical tensions escalated between India-China and India-Pakistan. An event window approach is employed to capture the impact of these events on herding behavior and information uncertainty in the considered stock indices. Multifractal Detrended Fluctuation Analysis (MFDFA) is applied to compute the Hurst value in all the trading days of the event window. The results of both indices exhibit conclusive evidence of herding and bubble formation during the overall period of geopolitical tensions between India-China and India-Pakistan. However, the degree of herding in the stock indices intensifies to a profound pattern when the tensions between India and China escalated into deadly violent clashes, and also during the heightened tensions between India and Pakistan that eventually ended up in airstrikes across the boundaries. The overall level of information uncertainty depicted by entropy is within control. The volatility in these stock indices has been confirmed to follow a unidirectional pattern.
\end{abstract}

Keywords

JEL Classification

\section{INTRODUCTION}

When there is a menace to normal associations between regions and nations, this is generally referred to as geopolitical tensions. Nations are said to face geopolitical tensions if their relationship with other nations is declined and divergent at various levels. However, their relationships can be largely defined at an economic, social, military and political levels. Any substantial shifts in these relationships can significantly influence market behavior and generate volatility in financial markets. Volatility plays a crucial role in financial markets, particularly concerning investment decisions (Poon \& Granger, 2003). In this regard, market participants are not only concerned about the nature of the volatility, but also about its level.

Given this, traders in financial markets differentiate market volatilities as good and bad (Giot et al., 2010). Good volatility is unidirectional, determined and moderately simple to foresee. On the contrary, bad volatility is restless and comparatively challenging to anticipate. Thus, good volatility can be related to the perpetual and continuous 
component, while bad volatility takes the irregular and discontinuous part (Gkillas et al., 2018). When the market volatility is unidirectional and persistent in large parts of the series, it is said to exhibit a profound pattern of the mindless following. This mindless following in financial terms is referred to as herding behavior. In simple terms, herding in the financial market means participants mindlessly mimicking the investment actions of others by suppressing their own beliefs. Herding is said to occur in financial markets when investors are challenged with unpredictability, uncertainty and extreme market volatility (Naresh et al., 2019).

Generally, events such as 'geopolitical tensions' between nations are bounded by market volatility and accompanied by the uncertainty of all kinds. Such extreme events are said to disturb the normal market behavior as they pose a huge challenge to the investors in assessing the direction of the market volatility and making a rational investment decision. Regardless of such a substantial extreme event and irrespective of its volatility direction, the core research question is to probe and discover the evidence of herding behavior in the market indices. Therefore, it would be rather interesting to investigate such extreme (geopolitical) events to explore for a definite conclusion. Thus, this empirical investigation attempts to demonstrate distinct degrees of herding in market indices during the two most important events of geopolitical tensions that occurred between India and its two neighboring nations China and Pakistan during 2020 and 2019, respectively.

Regardless of the cause for such geopolitical tensions, these extreme events present an element of shock to the markets. Also, market experts acknowledged that the benchmark index would have sensed a mammoth volume of negative bubble instigated by the herd behavior. Thus, a comparative investigation of market behavior using herding during those days of geopolitical tensions by employing robust econophysics tool of 'Hurst Exponent' cobbled with an event window approach makes this study unique.

\section{LITERATURE REVIEW}

Enormous studies in financial literature have examined the impact of geopolitical risks on financial assets and financial markets. They have adopted the Geopolitical Risk Index (GPI) as a key tool and examined its effect on the stock, currency and commodity markets in both emerging and developed markets worldwide. Some of the noteworthy recent studies include Antonakakis et al. (2017), Balcilar et al. (2018), Aysan et al. (2019), Das, Kannadhasan, and Bhattacharyya (2019), and Das, Kannadhasan, and Bhowmik (2019). Furthermore, it is also said that the events of geopolitical tensions often influence the behavior of financial market participants. Time and again, geopolitical risks have been cited by various market stakeholders, including investors, central bankers and financial media as one of the key determinants of investment decision-making (Caldara et al., 2018). Behavioral finance is a domain with both theoretical suggestions and empirical investigations that intend to elucidate the reasoning patterns of investors and the extent to which these impact their investment decision-making (Mertzanis \& Allam,
2018). Also, behavioral finance fundamentally proposes that participants in financial markets mimic the investment actions of others, particularly during turbulent times of panic, unpredictability and uncertainty (Dhall \& Singh, 2020). This mimicking habit among the investor's is termed as herding behavior (Naresh et al., 2019). The literature on herding behavior in financial markets using traditional approaches is immense and has increased rapidly with time. To accomplish the purpose of the study, this review focuses on works that examined herding behavior with an econophysics approach, for a better understanding of the results. Econophysics is fundamentally a unique domain that includes concepts from at least two different fields, namely mathematics and physics. It is a field for research that employs theories and approaches of statistical physics to ascertain and solve the problems in economics and finance (Garcia \& Ramos, 2019). Any phenomena of financial markets in econophysics are generally studied and gauged with the tool called 'Hurst exponent'.

Hurst exponent (Hurst, 1951) was originally employed to predict the flow of water level of the riv- 
er Nile in Egypt (Graves et al., 2017). The adapted usage of the Hurst exponent is an instrument to unearth several embedded features and phenomena in financial markets. Researchers in the field of econophysics, through their extensive research, has established that the Hurst exponent (HE) can be an effective and powerful instrument to examine several phenomena in financial markets such as predictability, efficiency, market memory, bubble formation and herding behavior. The popularity of such findings has been demonstrated and established through studies across markets and asset types of different countries. This review further emphasizes the findings by distinct research works worldwide, which has significantly contributed to the econophysics literature.

In this regard, Cajueiro and Tabakb (2006) employed the instrument of the Hurst exponent to examine the predictability, both short-run and long-run, in European emerging markets using the stock returns. The authors discovered profound evidence of long-range predictability in equity returns. Also, Cajueiro and Tabak (2005) conducted a study using the Hurst exponent to rank the efficiency levels of eleven Asian emerging markets and Latin American markets for the period between 1991 to 2004. The results based on the Hurst exponent trends revealed that the efficiency level of Asian markets was higher than Latin American market. Authors, including Hull and McGroarty (2014), measured market memory using the Hurst exponent method in twenty-two advanced emerging equity markets for a sixteen-year sample. Their findings showed profound and mild evidence of long memory in stock volatility and returns, respectively. Researchers have also proposed the Hurst exponent as a robust tool to measure and quantify herding behavior and nascent bubbles in financial markets. Recently, Ghosh et al. (2020) employed the Hurst exponent measure to detect the traces of herding behavior and market bubbles in five EURIBOR panel banks. Their study successfully detected the traces of herding and market bubbles in all the banks evaluated. Considering the abundant literature related to the use of the Hurst exponent measure and its applications to examine a variety of phenomena in financial markets, this study further focuses on the methodology to estimate the Hurst exponent value.
Literature indicates distinct approaches to estimate the value of the Hurst exponent in financial time series. For an intriguing review on the methodologies of the Hurst exponent in Econophysics, see Garcia and Ramos (2019). Among them, the Multifractal Detrended Fluctuation Analysis, also referred to as an MFDFA approach for estimating the Hurst exponent value developed by Kantelhardt et al. (2002), is said to be the most established and strongest method to analyze Hurst value in a non-stationary financial time series. In addition, this approach has been extensively applied by researchers to study the multifractal properties of several financial markets across the globe. Given the affluent literature concerning MFDFA and its applications in financial markets, this study will also focus on reviewing the empirical literature, studies that have employed MFDFA to estimate Hurst exponents and have established its accuracy both globally and domestically.

Indian authors Kumar and Deo (2009) studied the multifractal properties in Indian stock markets during 1997 to 2007 by using the MFDFA approach to estimate the Hurst exponent. Their findings established multifractality in Indian stock markets and concluded that MFDFA allowed a reliable characterization of multifractality in the financial markets. Furthermore, Ghosh et al. (2020) investigated bubble and herding in the top five EURIBOR panel banks from 2009 to 2017 using the MFDFA approach. They predicted bubble and herding in case of all the five banks investigated and concluded that MFDFA was more accurate than DFA. Very recently, Aslam et al. (2020) assessed the intraday multifractality of eight European stock exchanges during the COVID-19 pandemic between January to March 2020. The authors estimated the values of the Hurst exponent using MFDFA and found an overall presence of multifractality in European markets during the pandemic. In addition, the authors also added that the MFDFA is the most renowned technique through which a rich level of multifractality can be found in financial markets. In a latest, Milos et al. (2020) conducted a comparative investigation on the detection of multifractality in seven CEE stock markets of the EU using the MFDFA method. The authors detected the largest multifractality level in Bulgarian and Czech markets, while they detect- 
ed a lower multifractality level in Slovenian and Croatian markets. Due to the accurateness and robustness associated with the MFDFA approach, researchers worldwide in the recent times have extensively employed this technique and have been quite successful in establishing the multifractal properties of financial markets in a global level. Therefore, the same has been applied in this study to unearth the embedded herding and bubble phenomena.

In recent years, India has witnessed both high-level and growing geopolitical tensions with its neighboring nations of Pakistan and China, respectively. Such tensions are said to be one of the most significant market disruptors which participants need to wrestle in the upcoming years. Considerable studies exist today to examine how these geopolitical risks impact the returns and volatility of financial assets and financial markets. But, studies empirically examining the influence of events with geopolitical risks on the behavior of market participants are very few in number. Scarce evidence in the empirical research paves the way to investigate and analyze the impact of extreme events such as geopolitical tensions on the herding behavior of market participants, which propounds the central notion of this study.

\section{AIMS}

This empirical paper cardinally aims to investigate the impact of geopolitical tensions on the investors' behavior of the Indian stock market. For this, the paper attempts to detect the embedded traces of herd behavior, bubble formation and to quantify the level of information uncertainty in market indices during the events of geopolitical tensions using an event window approach.

\section{METHODOLOGY}

\subsection{Event description}

This study identified two significant events of geopolitical tensions that escalated between India and its two neighboring nations China and Pakistan during 2020 and 2019, respectively. A brief description of each event is furnished below.
Firstly, the relationship between India and China had been gradually declining over time, due to an extensive misperception concerning each other's targeted foreign policies and global determinations (Gokhale, 2021). But amid the COVID-19 pandemic when the nations are battling against the spread of the noxious Coronavirus, high-level geopolitical tensions flared up between India and China. On the intervening evening of June 15, 2020, the Indian army and the people's liberation army of China engaged in a violent face-off in the Galwan Valley of India that resulted in the death of twenty Indian troops and an indefinite number of Chinese causalities. This violent confrontation is considered the deadliest clash in the past four decades. Soon after the news confirming that tensions escalated into violence stroke the markets on June 16, 2020, the benchmark index CNX Nifty 50 erased all its gains and touched a low of 9,728.50, a drop of over 286 points from its trading days' open. Later, the index recovered its losses and closed at 9,914.00, a rise of close to 101 points from the previous day's close.

Subsequently, the relationship between India and Pakistan had mostly been extremely low since independence, but the ties between them touched a new low level when the deadly Pulwama terror attack took place on February 14, 2019, in Pulwama district of Kashmir, India, resulted in the death of forty-six Indian reserve police personnel. The following day, India accused Pakistan of backing terrorism and supporting terror groups to carry out attacks in India. However, Pakistan denied its role in the attack. As a retaliation to Pakistan, in the early morning hours of February 26, 2019, the Indian air force conducted massive airstrikes across the line of control and in Pakistan destroying most of its terror camps. The impact of the steeping tensions between India and Pakistan was sensed in the markets soon after the Indian foreign secretary confirmed that the Indian air force attacked the Balakot sector of Pakistan. The Nifty index, which was floating between $10,729.30$ and 10,888.75, later closed at 10,729.30, a fall of nearly 45 points from the previous day's close. Later, analysts confirmed that the index was about to surpass the 10,900 marks on the same day but the tensions deviated the direction of the markets. 


\subsection{Event date and event window}

Violent clashes between the Indian army and the people's liberation army of China took place on the intervening evening of June 15, 2020, in the Galwan Valley of India, but the news confirming that tensions had escalated into violence reached the markets on June 16, 2020. Therefore, June 16, 2020 is considered as the event day where day $=0$ i.e. $(t=0)$ to check the event's impact on herding behavior. To study the impact created by this extreme event on herding and bubble in markets accurately, an event window of 15 days before and after the event day is employed. Thus, for this event, the pre-event window is 15 trading days, consisting of day -15 to day -1 , and the post-event window is also 15 trading days, consisting of day +1 to day +15 .

The Indian air force conducted huge airstrikes across the line of control and in Pakistan in the early morning hours of February 26, 2019. Therefore, February 26, 2019 is considered as the event day where day $=0$ i.e. $(t=0)$ to check the event's impact on herding behavior. To study the impact created by this short event on herding behavior in markets very precisely, the event window is customized to just 10 days before and after the event day. Thus, for this event, the preevent window is 10 trading days, consisting of day -10 to day -1 , and the post-event window is also 10 trading days, consisting of day +1 to day +10 .

\subsection{Data and sources}

This study considered two main broad market indices of the National Stock Exchange (NSE), namely, CNX nifty 50 and CNX nifty 100, both in High Frequency Trading (HFT) domains. Initially, all the intraday index price per second data (tick-bytick) during the regular trading session between 09:15 am to $3: 30 \mathrm{pm}$ for the respective trading days in the event window was procured from NSE DotEx. However, due to duplicate time-stamping, all the repeated index prices of the trading day were removed, and only the unique index prices were finally considered for analysis. The list of trading days and their respective number of unique observations are presented in the results table of respective events.

\subsection{Model for herding behavior (Hurst exponent using MFDFA)}

As mentioned in the review section of this study, Multifractal Detrended Fluctuation Analysis (MFDFA) is said to be one of the renowned and well-established techniques to compute the value of the Hurst exponent in a noisy financial time series. This study employed the Multifractal Detrended Fluctuation Analysis originally established by Kantelhardt et al. (2002) followed in the works of Kumar and Deo (2009), Yim et al. (2014), Ghosh et al.(2020) and Aslam et al. (2020). Initially, the normalized log returns for the (tick-by-tick) index prices are calculated as defined below:

$$
x(t)=\ln \left(\frac{p_{t}}{p_{t-1}}\right) \text { of length } N,
$$

where $x(t)$ is the non-stationary time series of the market index in the (tick-by-tick) HFT domain for a trading day $(t), p_{t}$ represents the price of the index on tick $t$, and $p_{t-1}$ is the price of the index on tick $t-1$. The MFDFA methodology proposed by Kantelhardt et al. (2002) comprises five steps, which are as follows:

Step 1: The estimation of the profile:

$$
Y(i)=\sum_{k=1}^{i}[x(t)-\bar{x}], i=1, \ldots, N
$$

where $N$ is the total length of the time series, and $\bar{x}$ is the mean of the original time series $x(t)$.

Step 2: Division of the above profile $Y(i)$ into $N_{s}$ where $N_{s}=\operatorname{int}(N / s)$ non-overlapping parts of the length $s$. Since the whole time series length $N$ can be a non-multiple of the regarded time scale $s$, a small part of the series persists, the same process is repeated starting from the opposite end side. Thus, obtaining $2 N_{s}$ segments in total.

Step 3: Calculation of the local trend for individually obtained $2 N_{s}$ parts by a least-square fit of the time series. Determination of variance as follows:

$F^{2}(s, v) \equiv \frac{1}{s} \sum_{i=1}^{s}\left\{Y[(v-1) s+i]-y_{v(i)}\right\}^{2}$ 
For each segment $v, v=1, \ldots, N_{s}$ and

$F^{2}(s, v) \equiv$

$\equiv \frac{1}{s} \sum_{i=1}^{s}\left\{Y\left[N-\left(v-N_{s}\right) s+i\right]-y_{v(i)}\right\}^{2}$.

For $v=N_{s}+1 \ldots 2 N_{s}$. Here, $y_{v}(i)$ is the fitting polynomial in segment $v$.

Step 4: Obtaining the $q^{\text {th }}$ order fluctuation functions by averaging all the parts from step 2:

$$
F_{q}(s) \equiv\left\{\frac{1}{2 N_{s}} \sum_{v=1}^{2 N_{s}}\left[F^{2}(S, V)\right]^{q / 2}\right\}^{1 / q},
$$

where the variable $q$ can take any real value except zero.

Step 5: Determination of scaling behavior of the fluctuation functions by examining log-log plot of $F_{q}(s)$ versus $s$ for each value of $q$. If the time series $x(t)$ are long-range power-law correlated, $f_{q}(s)$ increases for a large value of $s$, as a power law.

$$
f_{q}(s) \sim s^{h(q)}
$$

where $h_{(q)}$ is the generalized Hurst exponent $(H)$ as referred to in the financial literature (Hurst, 1951). The values of the Hurst exponent generally range between 0 to 1 . The values of the Hurst exponent i.e., $5^{\text {th }}$ order Hurst exponent $(H)$ for each trading day in the event windows for respective events considered in this study, were computed using the above described MFDFA analysis. For this purpose, MATLAB software package with the coding established by Ihlen (2012) was employed, and the obtained results of $5^{\text {th }}$ order Hurst exponent $(H)$ were analyzed for the market indices and events considered for this study.

Since the market phenomenon 'herding' can be depicted by this powerful econophysics tool "Hurst exponent" combined with fractal dimension, therefore, the same has been employed in this empirical study. Apart from herd behavior, the analysis of the Hurst exponent is also an excellent tool to understand the fractal dimension $(D)$ i.e., $D=2-H$. The term fractal refers to a geometric form or a shape that measures the smoothness of any surface. The smoothness in this context refers to the volatility surface in the markets. The following is the table displaying various zones of the Hurst exponent $(H)$ and its interpretation for herding behavior (Table 1).

Table 1. Range of Hurst values and their respective interpretation

\begin{tabular}{l|l}
\hline Hurst range & $\begin{array}{c}\text { Interpretation for herding, bubble } \\
\text { and fractal dimension }\end{array}$ \\
\hline $0<H<0.5$ & $\begin{array}{l}\text { Absence of herding and bubble, more fractal } \\
\text { dimension (volatility) surface is rough }\end{array}$ \\
\hline$H=0.5$ & Random-walk, completely stochastic \\
\hline $0.5<H<0.64$ & $\begin{array}{l}\text { Mild herding and mild bubble, less fractal } \\
\text { dimension (volatility) surface is smooth }\end{array}$ \\
\hline $0.65<H<0.71$ & $\begin{array}{l}\text { High level herding and bubble, less fractal } \\
\text { dimension (volatility) surface is smooth }\end{array}$ \\
\hline $0.72<H<1.00$ & $\begin{array}{l}\text { Higher level herding and bubble, less fractal } \\
\text { dimension (volatility) surface is smoother }\end{array}$ \\
\hline
\end{tabular}

\subsection{Model for information uncertainty level (Shannon's entropy)}

The availability of information also plays a crucial role in leading the investors to herding behavior. The information needed to make a rational investment decision may not be available to every market participant. Even if it were, different investors receive different information at different time zones and react to the information differently. By this, it means, efficient market hypothesis (EMH) does not hold good in most of the real market cases. Hence, the aspect of uncertainty or complexity always exists in the market. Entropy is said to be the most successful tool to measure uncertainty and complexity. Shannon entropy is a calculation of information availability in a system $(\mathrm{Gu}, 2017)$. Therefore, the same has been employed to measure the level of information uncertainty for each trading day in the respective event windows of this event study. The formula is as follows:

$$
S_{\left(X_{i}\right)}=-\sum_{i=1}^{p} p\left(x_{i}\right) \log _{b} p\left(x_{i}\right) .
$$

where $p$ stands for its probability distribution, $x_{i}$ is a random variable accepting an infinite number of values $(1,2,3,4 \ldots n)$. Here, $x_{i}$ is taken as the time series of the market index in HFT domain for the trading day. $p\left(x_{i}\right)$ depicts the occurring probability 
of a single event, $-\log _{b} p\left(x_{i}\right)$ denotes the amount of information transmitted from the event. Therefore,

$$
-\sum_{i=1}^{p} p\left(x_{i}\right) \log _{b} p\left(x_{i}\right)
$$

is the statistical average value of the transmitted information from all such single events. This statistical average value is referred to as Shannon's entropy or information entropy, which is expressed as $S_{(X i)}$. If the obtained entropy value measures more than 3.5, it means the level of information uncertainty is away from the control, and if its measure is less than 3.5 , this means the information uncertainty level is inside the control.

\section{RESULTS AND ANALYSIS}

This segment provides the outcomes of the investigation concerning geopolitical tensions with two neighboring nations, China and Pakistan. The Hurst exponent and Shannon's entropy values are computed for each trading day in the event window for the considered two broad market indices.

\subsection{Geopolitical tensions event between India and China on CNX Nifty 50}

Table 2. Illustrating the results of Hurst, Fractal dimension and Entropy for CNX Nifty 50

\begin{tabular}{|c|c|c|c|c|c|}
\hline Date & Event window $(t)$ & Number of observations & HE & FD & SE \\
\hline May 26, 2020 & $(t=-15)$ & 2907 & 0.63041 & 1.36959 & 3.48306 \\
\hline May 27, 2020 & $(t=-14)$ & 5179 & 0.74809 & 1.25191 & 3.52219 \\
\hline May 28, 2020 & $(t=-13)$ & 2635 & 0.41457 & 1.58543 & 3.46182 \\
\hline May 29, 2020 & $(t=-12)$ & 3571 & 0.60031 & 1.39969 & 3.42591 \\
\hline June 1, 2020 & $(t=-11)$ & 2819 & 0.58648 & 1.41352 & 3.44797 \\
\hline June 2, 2020 & $(t=-10)$ & 3048 & 0.59743 & 1.40257 & 3.37047 \\
\hline June 3, 2020 & $(t=-9)$ & 2572 & 0.38206 & 1.61794 & 3.34974 \\
\hline June 4, 2020 & $(t=-8)$ & 3282 & 0.62509 & 1.37491 & 3.45501 \\
\hline June 5, 2020 & $(t=-7)$ & 2566 & 0.59504 & 1.40496 & 3.34475 \\
\hline June 8, 2020 & $(t=-6)$ & 3412 & 0.60922 & 1.39078 & 3.44897 \\
\hline June 9, 2020 & $(t=-5)$ & 4637 & 0.66249 & 1.33751 & 3.42371 \\
\hline June 10, 2020 & $(t=-4)$ & 2076 & 0.53889 & 1.46111 & 3.34624 \\
\hline June 11, 2020 & $(t=-3)$ & 4003 & 0.48072 & 1.51928 & 3.47200 \\
\hline June 12, 2020 & $(t=-2)$ & 5784 & 0.48415 & 1.51585 & 3.46148 \\
\hline June 15,2020 & $(t=-1)$ & 3873 & 0.64612 & 1.35388 & 3.46766 \\
\hline June 16, 2020 & $(t=0)$ & 5003 & 0.64526 & 1.35474 & 3.48667 \\
\hline June 17, 2020 & $(t=+1)$ & 3024 & 0.59685 & 1.40315 & 3.37195 \\
\hline June 18, 2020 & $(t=+2)$ & 4325 & 0.59499 & 1.40501 & 3.49152 \\
\hline June 19, 2020 & $(t=+3)$ & 3591 & 0.51492 & 1.48508 & 3.40255 \\
\hline June 22, 2020 & $(t=+4)$ & 2221 & 0.49103 & 1.50897 & 3.49128 \\
\hline June 23, 2020 & $(t=+5)$ & 3197 & 0.48286 & 1.51714 & 3.50133 \\
\hline June 24,2020 & $(t=+6)$ & 4786 & 0.66272 & 1.33728 & 3.49099 \\
\hline June 25,2020 & $(t=+7)$ & 3057 & 0.66333 & 1.33667 & 3.48126 \\
\hline June 26,2020 & $(t=+8)$ & 1799 & 0.50563 & 1.49437 & 3.48041 \\
\hline June 29, 2020 & $(t=+9)$ & 2132 & 0.46688 & 1.53312 & 3.49287 \\
\hline June 30, 2020 & $(t=+10)$ & 2248 & 0.58635 & 1.41365 & 3.50790 \\
\hline July 01, 2020 & $(t=+11)$ & 2670 & 0.63359 & 1.36641 & 3.47704 \\
\hline July 02, 2020 & $(t=+12)$ & 2056 & 0.53248 & 1.46752 & 3.39006 \\
\hline July 03, 2020 & $(t=+13)$ & 1304 & 0.59452 & 1.40548 & 3.44255 \\
\hline July 06, 2020 & $(t=+14)$ & 2174 & 0.45703 & 1.54297 & 3.46666 \\
\hline July 07, 2020 & $(t=+15)$ & 2285 & 0.43249 & 1.56751 & 3.47354 \\
\hline
\end{tabular}



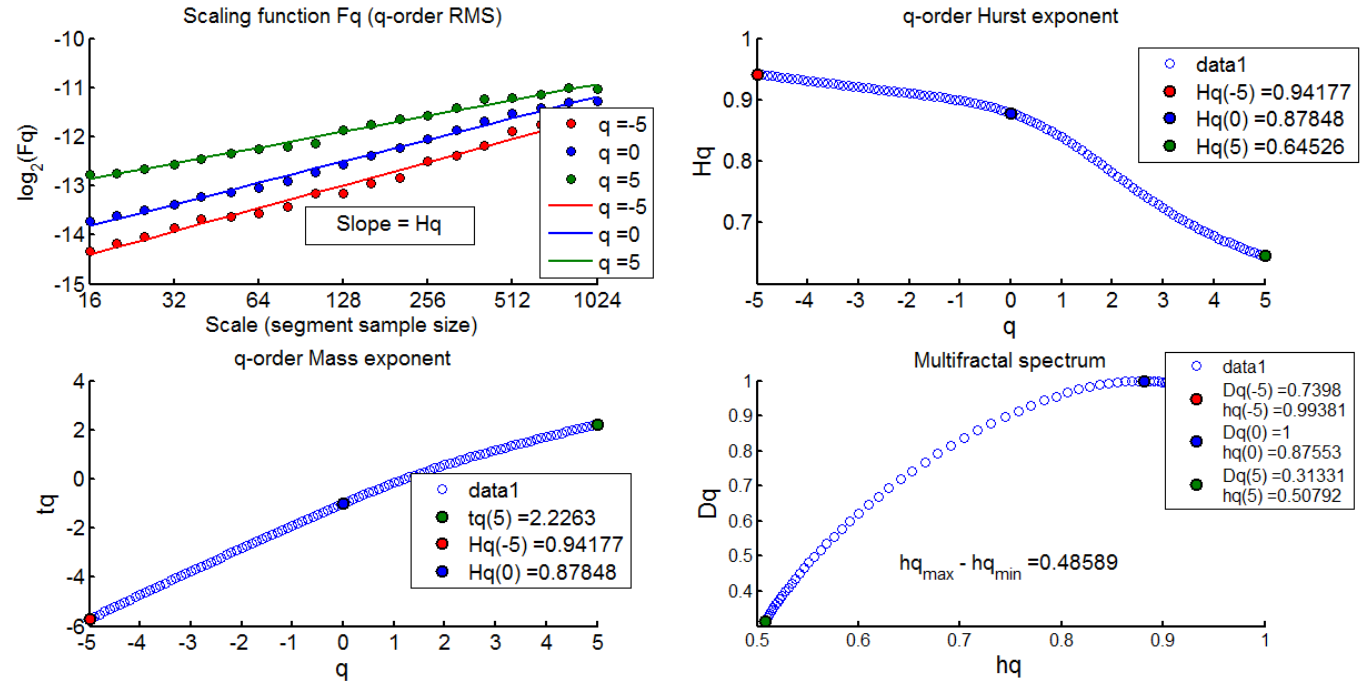

Figure 1. The $5^{\text {th }}$ order Hurst exponent $(H)$ of CNX Nifty 50 on the event day June 16,2020 , i.e., $(t=0)$

\subsection{Geopolitical tensions event between India and China on CNX Nifty 100}

Table 3. Illustrating the results of Hurst, Fractal dimension and Entropy for CNX Nifty 100

\begin{tabular}{|c|c|c|c|c|c|}
\hline Date & Event window (t) & Number of observations & HE & FD & SE \\
\hline May 26, 2020 & $(t=-15)$ & 2738 & 0.64237 & 1.35763 & 3.47277 \\
\hline May 27,2020 & $(t=-14)$ & 4904 & 0.65969 & 1.34031 & 3.51267 \\
\hline May 28, 2020 & $(t=-13)$ & 2655 & 0.50781 & 1.49219 & 3.41789 \\
\hline May 29, 2020 & $(t=-12)$ & 3765 & 0.62041 & 1.37959 & 3.47679 \\
\hline June 1,2020 & $(t=-11)$ & 2709 & 0.56166 & 1.43834 & 3.47298 \\
\hline June 2,2020 & $(t=-10)$ & 2842 & 0.55436 & 1.44564 & 3.33565 \\
\hline June 3,2020 & $(t=-9)$ & 2585 & 0.42172 & 1.57828 & 3.47361 \\
\hline June 4, 2020 & $(t=-8)$ & 3337 & 0.69775 & 1.30225 & 3.42086 \\
\hline June 5,2020 & $(t=-7)$ & 2685 & 0.64509 & 1.35491 & 3.49466 \\
\hline June 8,2020 & $(t=-6)$ & 3340 & 0.65728 & 1.34272 & 3.51356 \\
\hline June 9, 2020 & $(t=-5)$ & 4612 & 0.59776 & 1.40224 & 3.52213 \\
\hline June 10, 2020 & $(t=-4)$ & 2043 & 0.5501 & 1.4499 & 3.48301 \\
\hline June 11,2020 & $(t=-3)$ & 4071 & 0.53339 & 1.46661 & 3.43075 \\
\hline June 12,2020 & $(t=-2)$ & 5831 & 0.48693 & 1.51307 & 3.52312 \\
\hline June 15,2020 & $(t=-1)$ & 3847 & 0.66895 & 1.33105 & 3.47492 \\
\hline June 16,2020 & $(t=0)$ & 4896 & 0.67719 & 1.32281 & 3.44067 \\
\hline June 17,2020 & $(t=+1)$ & 2904 & 0.55493 & 1.44507 & 3.35585 \\
\hline June 18,2020 & $(t=+2)$ & 3973 & 0.57025 & 1.42975 & 3.40895 \\
\hline June 19,2020 & $(t=+3)$ & 3394 & 0.56522 & 1.43478 & 3.51644 \\
\hline June 22,2020 & $(t=+4)$ & 2224 & 0.52268 & 1.47732 & 3.44020 \\
\hline June 23,2020 & $(t=+5)$ & 3185 & 0.49704 & 1.50296 & 3.43927 \\
\hline June 24,2020 & $(t=+6)$ & 4901 & 0.71929 & 1.28071 & 3.49744 \\
\hline June 25,2020 & $(t=+7)$ & 3026 & 0.67722 & 1.32278 & 3.44778 \\
\hline June 26,2020 & $(t=+8)$ & 1890 & 0.52943 & 1.47057 & 3.38926 \\
\hline June 29,2020 & $(t=+9)$ & 2032 & 0.4817 & 1.5183 & 3.45953 \\
\hline June 30,2020 & $(t=+10)$ & 2260 & 0.54513 & 1.45487 & 3.45593 \\
\hline July 01, 2020 & $(t=+11)$ & 2420 & 0.6684 & 1.3316 & 3.41063 \\
\hline July 02, 2020 & $(t=+12)$ & 1970 & 0.49372 & 1.50628 & 3.50369 \\
\hline July 03, 2020 & $(t=+13)$ & 1245 & 0.48838 & 1.51162 & 3.46888 \\
\hline July 06, 2020 & $(t=+14)$ & 1939 & 0.40135 & 1.59865 & 3.49737 \\
\hline July 07, 2020 & $(t=+15)$ & 2299 & 0.44981 & 1.55019 & 3.50854 \\
\hline
\end{tabular}



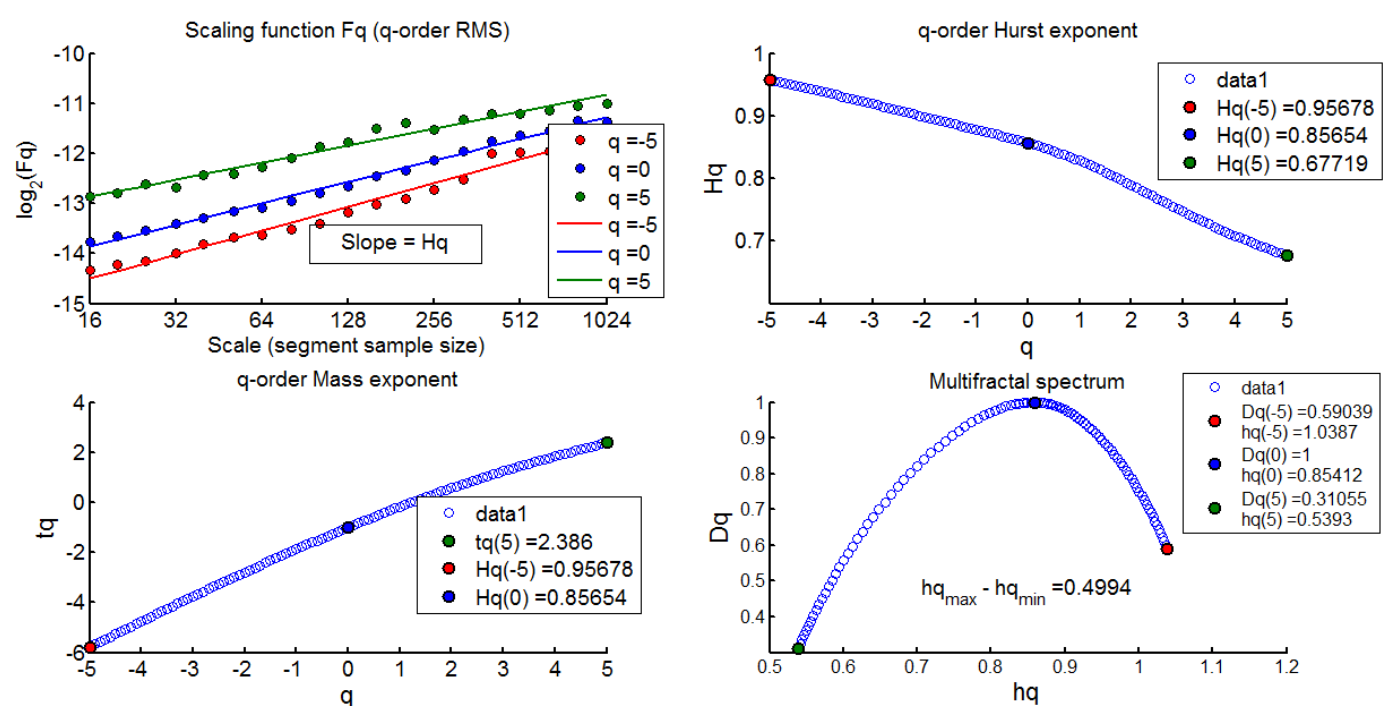

Figure 2. The $5^{\text {th }}$ order Hurst exponent $(H)$ of CNX Nifty 100 on event day June 16,2020 , i.e., $(t=0)$

Source: Author's development.

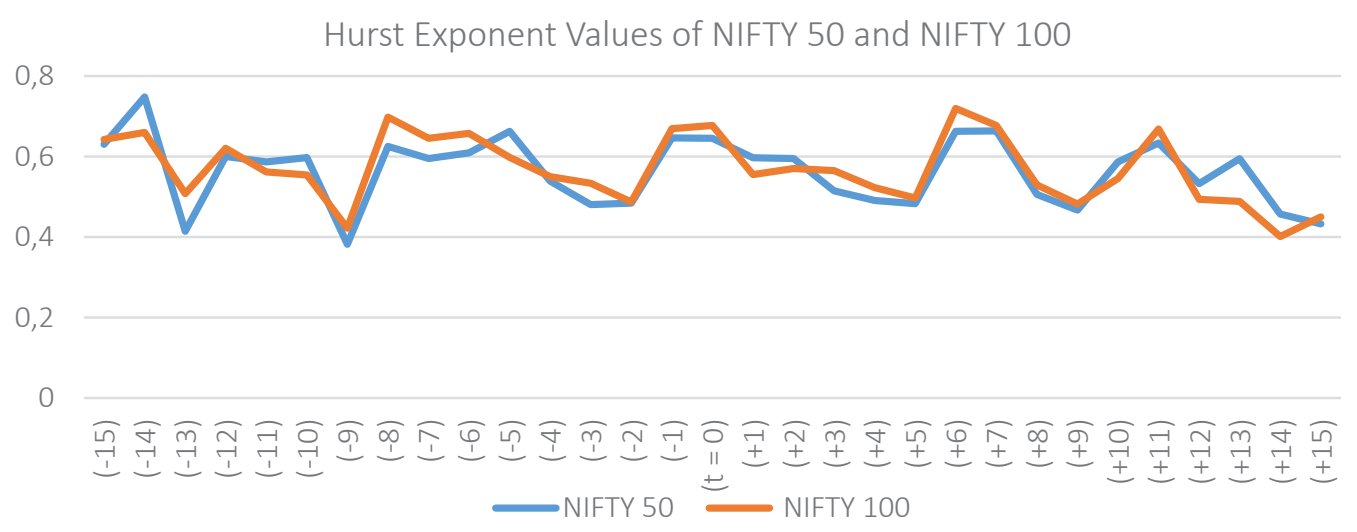

Figure 3. Hurst exponent $(H)$ values in the event window for India-China geopolitical tensions event

\subsection{Geopolitical tensions event between India and Pakistan on CNX Nifty 50}

Table 4. Illustrating the results of Hurst, Fractal dimension and Entropy for CNX Nifty 50

\begin{tabular}{|c|c|c|c|c|c|}
\hline Date & Event window $(t)$ & $\begin{array}{c}\text { Number of } \\
\text { observations }\end{array}$ & $\mathrm{HE}$ & FD & SE \\
\hline February 12, 2019 & $(t=-10)$ & 1466 & 0.47041 & 1.52959 & 3.49194 \\
\hline February 13, 2019 & $(t=-9)$ & 1960 & 0.50206 & 1.49794 & 3.49148 \\
\hline February 14, 2019 & $(t=-8)$ & 1230 & 0.38432 & 1.61568 & 3.46257 \\
\hline February 15, 2109 & $(t=-7)$ & 2364 & 0.49589 & 1.50411 & 3.51203 \\
\hline February 18, 2019 & $(t=-6)$ & 1807 & 0.33673 & 1.66327 & 3.50026 \\
\hline February 19, 2019 & $(t=-5)$ & 2355 & 0.45011 & 1.54989 & 3.46568 \\
\hline February 20, 2019 & $(t=-4)$ & 1654 & 0.42017 & 1.57983 & 3.51060 \\
\hline February 21, 2019 & $(t=-3)$ & 1658 & 0.43452 & 1.56548 & 3.49277 \\
\hline February 22, 2019 & $(t=-2)$ & 822 & 0.55968 & 1.44032 & 3.44981 \\
\hline February 25, 2019 & $(t=-1)$ & 1848 & 0.61502 & 1.38498 & 3.47546 \\
\hline February 26, 2019 & $(t=0)$ & 2973 & 0.58726 & 1.41272 & 3.48666 \\
\hline February 27, 2019 & $(t=+1)$ & 3394 & 0.69742 & 1.30258 & 3.51310 \\
\hline February 28, 2019 & $(t=+2)$ & 1293 & 0.57863 & 1.42137 & 3.48516 \\
\hline March 1, 2019 & $(t=+3)$ & 1061 & 0.37359 & 1.62641 & 3.49681 \\
\hline
\end{tabular}


Table 4 (cont.). Illustrating the results of Hurst, Fractal dimension and Entropy for CNX Nifty 50

\begin{tabular}{|c|c|c|c|c|c|}
\hline Date & Event window $(t)$ & $\begin{array}{c}\text { Number of } \\
\text { observations }\end{array}$ & HE & FD & SE \\
\hline March 5, 2019 & $(t=+4)$ & 2886 & 0.51740 & 1.4826 & 3.51009 \\
\hline March 6, 2019 & $(t=+5)$ & 1139 & 0.43222 & 1.56778 & 3.27462 \\
\hline March 7, 2019 & $(t=+6)$ & 1220 & 0.32535 & 1.67465 & 3.35399 \\
\hline March 8, 2019 & $(t=+7)$ & 787 & 0.53058 & 1.46942 & 3.27359 \\
\hline March 11, 2019 & $(t=+8)$ & 1703 & 0.60047 & 1.39953 & 3.15133 \\
\hline March 12, 2019 & $(t=+9)$ & 1490 & 0.50196 & 1.49804 & 3.36295 \\
\hline March 13, 2019 & $(t=+10)$ & 1423 & 0.47953 & 1.52047 & 3.33130 \\
\hline
\end{tabular}
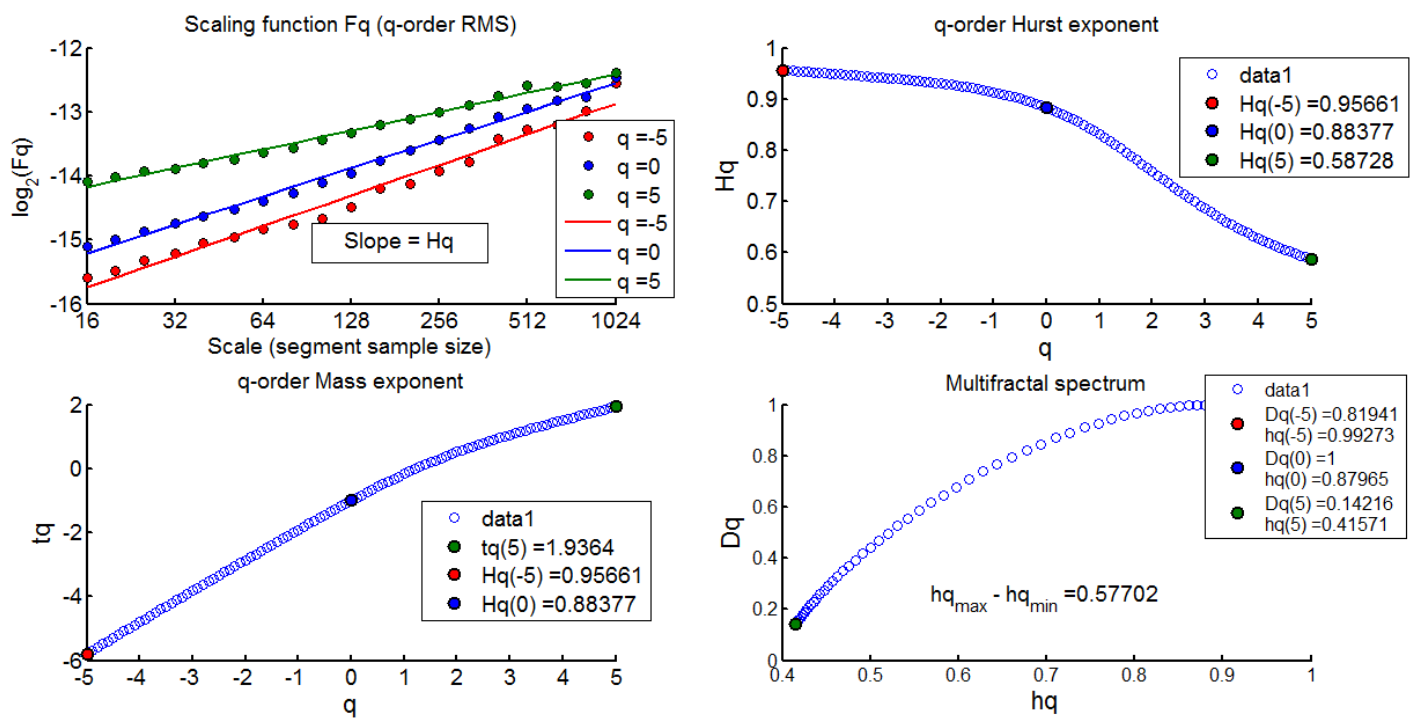

Figure 4. The $5^{\text {th }}$ order Hurst exponent $(H)$ of CNX Nifty 50 on the event day February 26, 2019, i.e., $(t=0)$

\subsection{Geopolitical tensions event between India and Pakistan on CNX Nifty 100}

Table 5. Illustrating the results of Hurst, Fractal dimension and Entropy for CNX Nifty 100

\begin{tabular}{|c|c|c|c|c|c|}
\hline Date & Event window $(t)$ & Number of observations & HE & FD & SE \\
\hline February 12, 2019 & $(t=-10)$ & 1534 & 0.43869 & 1.56131 & 3.41184 \\
\hline February 13, 2019 & $(t=-9)$ & 2031 & 0.44370 & 1.5563 & 3.42529 \\
\hline February 14, 2019 & $(t=-8)$ & 1204 & 0.31137 & 1.68863 & 3.45418 \\
\hline February 15, 2109 & $(t=-7)$ & 2440 & 0.49018 & 1.50982 & 3.50464 \\
\hline February 18, 2019 & $(t=-6)$ & 1690 & 0.42225 & 1.57775 & 3.49141 \\
\hline February 19, 2019 & $(t=-5)$ & 2339 & 0.46172 & 1.53828 & 3.51282 \\
\hline February 20, 2019 & $(t=-4)$ & 1641 & 0.44188 & 1.55812 & 3.47323 \\
\hline February 21, 2019 & $(t=-3)$ & 1687 & 0.47347 & 1.52653 & 3.49488 \\
\hline February 22, 2019 & $(t=-2)$ & 859 & 0.55211 & 1.44789 & 3.42267 \\
\hline February 25, 2019 & $(t=-1)$ & 1778 & 0.67978 & 1.32022 & 3.44424 \\
\hline February 26, 2019 & $(t=0)$ & 3118 & 0.54684 & 1.45316 & 3.46557 \\
\hline February 27, 2019 & $(t=+1)$ & 3473 & 0.69753 & 1.30247 & 3.42738 \\
\hline February 28, 2019 & $(t=+2)$ & 1195 & 0.52243 & 1.47757 & 3.42881 \\
\hline March 1, 2019 & $(t=+3)$ & 1071 & 0.28249 & 1.71751 & 3.27223 \\
\hline March 5, 2019 & $(t=+4)$ & 2975 & 0.51800 & 1.48200 & 3.24698 \\
\hline March 6, 2019 & $(t=+5)$ & 1116 & 0.44773 & 1.55227 & 3.24379 \\
\hline
\end{tabular}


Table 5 (cont.). Illustrating the results of Hurst, Fractal dimension and Entropy for CNX Nifty 100

\begin{tabular}{|c|c|c|c|c|c|}
\hline Date & Event window $(t)$ & Number of observations & HE & FD & SE \\
\hline March 7, 2019 & $(t=+6)$ & 1158 & 0.29929 & 1.70071 & 3.28935 \\
\hline March 8, 2019 & $(t=+7)$ & 829 & 0.67017 & 1.32983 & 3.21765 \\
\hline March 11, 2019 & $(t=+8)$ & 1933 & 0.56993 & 1.43007 & 3.33227 \\
\hline March 12, 2019 & $(t=+9)$ & 1333 & 0.49467 & 1.50533 & 3.31303 \\
\hline March 13, 2019 & $(t=+10)$ & 1259 & 0.71542 & 1.28458 & 3.30484 \\
\hline
\end{tabular}
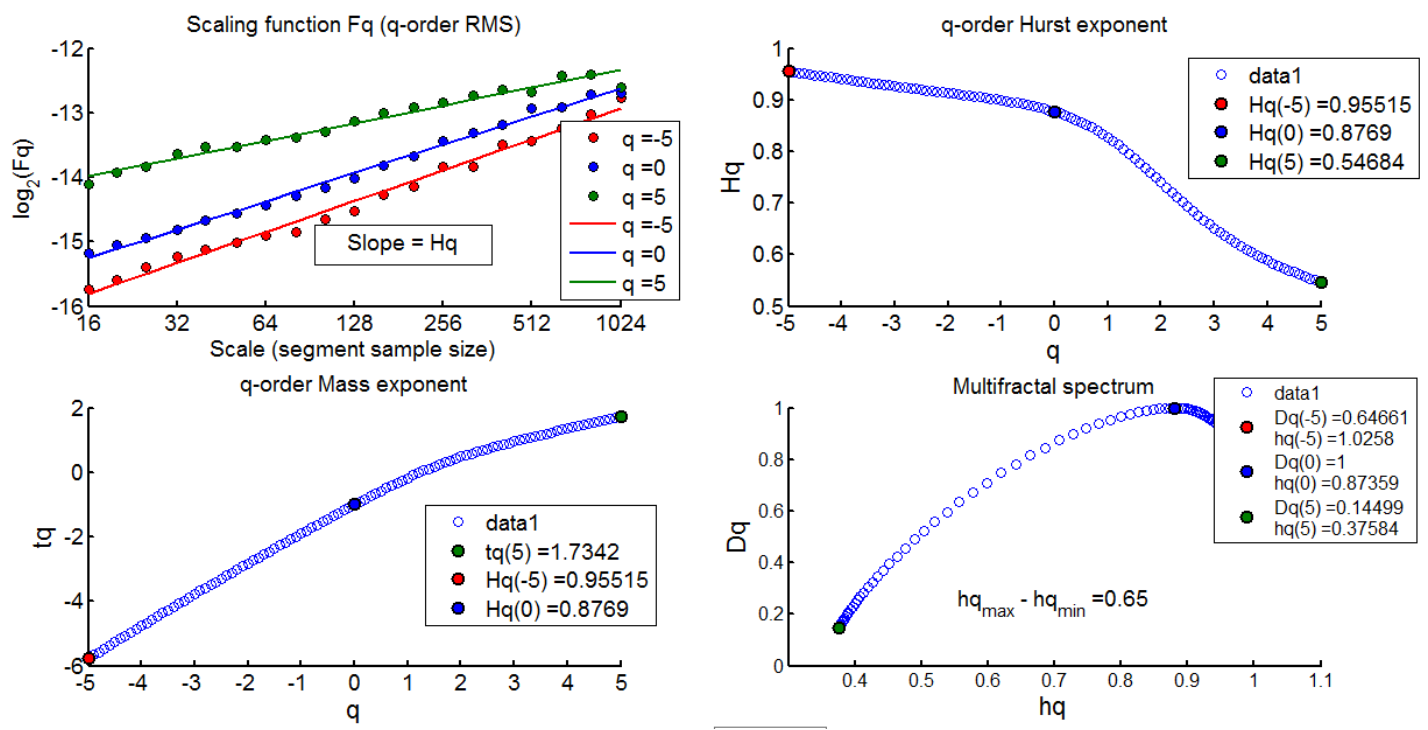

Figure 5. The $5^{\text {th }}$ order Hurst exponent $(H)$ of CNX Nifty 100 on the event day February 26, 2019, i.e., $(t=0)$

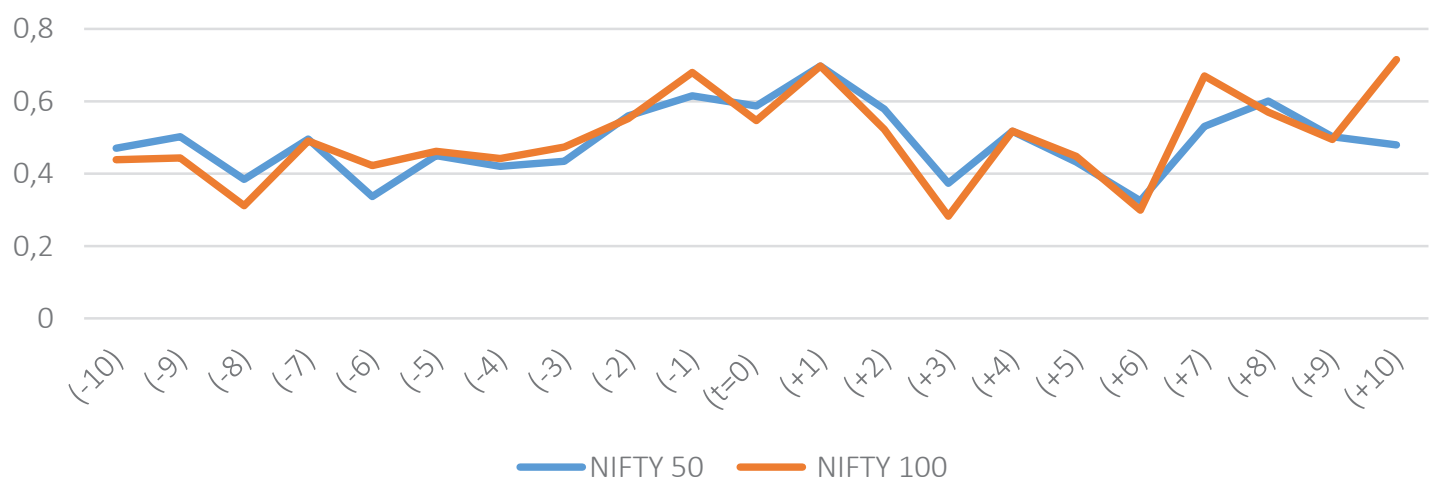

Figure 6. Hurst exponent $(\mathrm{H})$ values in the event window for India-Pakistan geopolitical tensions event

\section{DISCUSSION}

The whole empirical investigation is interpreted based on the outcomes obtained by computing the values of Hurst and Shannon's entropy to understand the behavior of the market using event windows during those days of geopolitical tensions.
In the case of geopolitical tensions between India and China, the empirical results for CNX Nifty 50 HFT domain (see Table 2) showed an average Hurst value of 0.573405 in the index for the pre-event window of -15 days, which indicates mild herding and little bubble formation. Eventually, the value of Hurst increased to 0.64526 (close to 0.65) (see 
Figure 1) tracing a high herding behavior and high bubble formation in the index on the event day i.e., $t=0$. Also, an average Hurst value of 0.547711 was observed in the post-event window of +15 days, denoting the existence of mild herding and bubbles in the index even after the occurrence of the event. Generally, for herding degree with Hurst values between $0.5<H<1$, the fractal dimension will be lesser, depicting smoothness in volatility surface; the same exists in this case. Also, Shannon's entropy measure of less than 3.5 throughout this event means that the information cascading has happened properly i.e., information is coming out of a source and reaching out to the market participants in the same flow, therefore, the level of information uncertainty seemed to be within the control.

In the case of CNX Nifty 100 HFT domain (see Table 3) for the same event, the empirical results showed an average Hurst value of 0.587018 and 0.544303 in the index for the pre-and post-event windows, respectively. This means again mild herding and little bubble formation existed in the index. Interestingly, the Hurst value clocked to 0.67719 on the event day (see Figure 2) establishing a profound herd behavior and high bubble formation in the index. The fractal dimension was found to be lesser across the event windows in this case, representing smoothness in volatility surface. Also, a low-level information uncertainty indicated by the entropy scale of less than 3.5 throughout this event shows that it is within the control.

Moving on to the geopolitical tensions between India and Pakistan, the market index CNX Nifty HFT 50 HFT domain (see Table 4) displayed an average Hurst value of 0.46689 , which is less than 0.5 , showing no traces of herding and bubble for the pre-event window period. Here, the average value of fractal dimension is quite high, which indicates the roughness in its volatility surface for the same. But on the day of the event, the Hurst value hiked to 0.58728 (see Figure 4), indicating herding and bubble in the index to an extent. The herding and bubble remained to continue in a very mild form for the post-event window, which is evidenced by an average Hurst value of 0.503715 . The average fractal dimension was found to be lesser for the post-event window, which represents smoothness in volatility surface. Shannon's entropy measure of less than 3.5 throughout this event means that the level of information uncertainty seemed to be within control.

In the case of CNX Nifty 100 HFT domain (see Table 5) for the same event, the empirical results showed an average Hurst value of 0.471515 , leaving again no traces of bubble and herding for the pre-event window period. But the Hurst value rose to 0.54684 on the day of the event (see Figure 5), demonstrating a low degree of herding and bubble. The herding and bubble remained to continue in a low-level form for the post-event window, which is demonstrated by an average Hurst value of 0.521766 . The average fractal dimension was found to be lesser for the post-event window, representing smoothness in volatility surface. Shannon's entropy was less than 3.5 throughout this event, which means that the level of information uncertainty was within control.

Furthermore, a comparative analysis of market behavior for both these geopolitical events leads to some intriguing findings. For this, this study considers the behavior of market indices on day $(-1)$, event day (0) and day (+1), for each event individually. The observation for CNX Nifty 50 and 100 during geopolitical tensions between India and China from Tables 2 and 3 and Figure 3, respectively, indicates very profound and strong herding on day (-1) and event day (0). This can be due to the arrival of panic-stricken news to the markets confirming that tensions escalated into high violence and the death of twenty Indian army soldiers. Eventually, the herding level for both indices gradually reduced to mild and low-level herding on the following day (see Figure 3) i.e., day $(+1)$.

On the other hand, during the geopolitical tensions between India and Pakistan (see Tables 4 and 5 and Figure 6), the market index CNX Nifty 50 and 100 demonstrated mild herding on day $(-1)$ and event day (0). But they displayed profound, strong and high herding and high bubble formation with a Hurst value of 0.69 on the following day i.e., day $(+1)$. This is because market participants very much expected retaliation event from the Indian end for the deadly terror attack on February 14, 2019. Further, the traces of bubble and herding gradually weakened in the last days of the post-event window. 
Another interesting observation that emerged out of this investigation is that the degree or level of herding and bubble is country-specific. The overall average Hurst value during the days of geopolitical tensions between India and China was 0.56 for both indices. But the same was close to just 0.51 during the days of geopolitical tensions between India and Pakistan. Moreover, when India had considerable number of skirmishes with Pakistan in the past at the line of action, the Indian markets always bounced back because the outcome of the event has always been de-escalation process at the end of the day, gradually reducing the tension levels on both the sides. But tensions with China is a different issue altogether. This was the deadliest face-off that India and China witnessed in the last four decades since the 1962 war. Having geopolitical tensions with a superpower nation like China, the markets want to witness some de-escalation process at the disputed borders to regain its normalcy. Any further tensions escalated between India and China will open up a fresh risk for Indian markets. In a nutshell, the results suggest that the geopolitical tensions escalated with China was relatively riskier to the Indian markets and its participants than those heightened tensions with Pakistan.

\section{CONCLUSION}

In this study, the impact of extreme events such as geopolitical tensions with China and Pakistan is examined on herding behavior of investors and bubble formation in the Indian stock market in relation to two broad indices (CNX Nifty 50 and CNX Nifty 100) using the Hurst exponent (HE) parameter. The key empirical results of the study successfully unearthed the embedded footprints of herding and bubble formation in the stock indices evaluated during the event investigation. In addition, the findings also state that the higher the Hurst value, the lower the fractal dimensions or roughness in the volatility surface, depicting a higher degree of predictability and herding. However, the overall scale of Shannon's entropy indicated that the information cascading among market participants during the event periods had taken place appropriately, and therefore, the level of information uncertainty (measured less than 3.5) is within the control. The study concludes that such extreme geopolitical tensions are usually bounded by inevitable market volatility, instigating investors to mindlessly follow or herd the investment actions of the masses. It also finds that the market volatility was unidirectional in its form, since it produced clear traces of herd behavior in most of the trading days around the event window.

In recent years, geopolitical uncertainties emerged as one of the significant market factors in emerging markets. Understanding the dependence relationships between geopolitical events and the way investors react to such uncertainties becomes crucial to make a rational investment decision. In this context, the findings of this study can be a key driver for stock market participants in making buy or sell decisions in the Indian market during an extreme event like geopolitical tensions. Further, these results will support them in investment decision-making in terms of risk diversification. In addition, investors can develop appropriate hedging strategies to prepare their portfolios for potential future geopolitical risks. This could also be useful for market analysts to understand the mind-set of investors and how markets respond as a whole. Moreover, through the effective application of the Hurst exponent tool, an estimation of upcoming impacts on the markets could be projected, which results in further advice for trading strategies during the de-escalation process. Research on traces of herding and bubble in key sector indices of the markets during times of geopolitical uncertainties is highly encouraged as an area of further study.

\section{AUTHOR CONTRIBUTIONS}

Conceptualization: Krishna T. A.

Data curation: Krishna T. A., Suresha B.

Formal analysis: Krishna T. A. 
Investigation: Krishna T. A., Suresha B.

Methodology: Krishna T. A.

Software: Krishna T. A.

Validation: Krishna, T. A., Suresha B.

Visualization: Krishna T. A., Suresha B.

Writing-original draft: Krishna T. A.

Writing - review and editing: Krishna T. A., Suresha B.

\section{ACKNOWLEDGEMENTS:}

The authors express their sincere thanks of gratitude to Dr. Bikramaditya Ghosh (Professor, Department of Finance and Analytics, RV Institute of Management, Bangalore, India) for his instrumental role in encouraging and motivating them to accomplish this research task. The authors also extend their sincere thanks to Dr. Manu K.S. (Assistant Professor, School of business and management, CHRIST (Deemed to be university), Bangalore, India) for his continued support throughout this empirical investigation.

\section{REFERENCES}

1. Antonakakis, N., Gupta, R., Kollias, C., \& Papadamou, S. (2017). Geopolitical risks and the oil-stock nexus over 18992016. Finance Research Letters, 23(C), 165-173. https://doi. org/10.1016/j.frl.2017.07.017

2. Aslam, F., Mohti, W., \& Ferreira, P. (2020). Evidence of Intraday Multifractality in European Stock Markets during the Recent Coronavirus (COVID-19) Outbreak. International Journal of Financial Studies, 8(31). https://doi.org/10.3390/ ijfs 8020031

3. Aysan, A., Dermir, E., Gozgor, G., \& Lau, C. K. (2019). Effects of the geopolitical risks on Bitcoin returns and volatility. Research in International Business and Finance, 47(C), 511-518. https://doi.org/10.1016/j. ribaf.2018.09.011

4. Balcilar, M., Bonato, M., Demirer, R., \& Gupta, R. (2018). Geopolitical risks and stock market dynamics of the BRICS. Economic Systems, 42(2), 295306. https://doi.org/10.1016/j. ecosys.2017.05.008

5. Cajueiro, D., \& Tabak, B. (2005). Ranking efficiency for emerging equity markets II. Chaos, Solitons \& Fractals, 23(2), 671-
675. https://doi.org/10.1016/j. chaos.2004.05.009

6. Cajueiro, D., \& Tabakb, B. (2006). Testing the predictability in equity returns for European transition markets. Economic Systems, 30(1), 56-78. https://doi. org/10.1016/j.ecosys.2005.09.003

7. Caldara, Dario, \& Lacoviello, M. (2018). Measuring Geopolitical Risk. International Finance Discussion Papers, 1222. https://doi.org/10.17016/ IFDP.2018.1222

8. Das, D., Kannadhasan, M., \& Bhattacharyya, M. (2019). Do the emerging stock markets react to international economic policy uncertainty, geopolitical risk and financial stress alike? The North American Journal of Economics and Finance, 49, 1-19. https://doi. org/10.1016/j.najef.2019.01.008

9. Das, D., Kannadhasan, M., \& Bhowmik, P. (2019). Geopolitical risks and precious metals. Journal of Economic Research, 49-66.

10. Dhall, R., \& Singh, B. (2020). The COVID-19 Pandemic and Herding Behaviour: Evidence from India's Stock Market. Millennial Asia, 11(3), 366-390. https://doi.org/10.1177\%2F0976399620964635
11. Garcia, M. d., \& Ramos, J. P. (2019). Different methodologies and uses of the hurst exponent in econophysics. Studies of Applied Economics, 37(2). http://dx.doi.org/10.25115/eea. v37i2.2603

12. Ghosh, B., Roux, C. L., \& Verma, A. (2020). Investigation of the fractal footprint in selected EURIBOR panel banks. Banks and bank system, 15(1), 185-198. https://dx.doi.org/10.21511/ bbs.15(1).2020.17

13. Giot, P., Laurent, S., \& Petitjean, M. (2010). Trading activity, realized volatility and jumps. Journal of Empirical Finance, 17(1), 168-175. https:// doi.org/10.1016/j.jempfin.2009.07.001

14. Gkillas, K., Gupta, R., \& Wohar, M. (2018). Volatility Jumps: The Role of Geopolitical Risks. Finance Research Letters. https:// doi.org/10.1016/j.frl.2018.03.014

15. Gokhale, V. (2021, March). The Road from Galwan: The Future of India-China Relations. Carnegie endowment for international peace. New Delhi, New Delhi - 110016, India: Carnegie India.

16. Graves, T., Gramacy, R., Watkins, N., \& Franzke, C. (2017). A 
Brief History of Long Memory: Hurst, Mandelbrot and the Road to ARFIMA, 1951-1980. Entropy, 19(9), 437. https://doi. org/10.3390/e19090437

17. Gu, R. (2017). Multiscale Shannon entropy and its application in the stock market. Physica A: Statistical Mechanics and its Applications, 484(15), 215-224. https://doi. org/10.1016/j.physa.2017.04.164

18. Hull, M., \& McGroarty, F. (2014). Do emerging markets become more efficient as they develop? Long memory persistence in equity indices. Emerging Markets Review, 18, 45-61. https://doi.org/10.1016/j.ememar.2013.11.001

19. Hurst, H. E. (1951). Long-term storage capacity of reservoirs. Transactions of the American Society of Civil Engineers, 116, 770-808.

20. Ihlen, E. A. (2012). Introduction to multifractal detrended fluctuation analysis in Matlab. Frontiers in Physiology, 1-18. https://doi.org/10.3389/

fphys.2012.00141

21. Kantelhardt, J., Zschiegner, S., Koscielny-Bunde, E., Havlin, S., Bunde, A., \& Stanley, H. (2002). Multifractal detrended fluctuation analysis of nonstationary time series. Physica A: Statistical Mechanics and its Applications, 316(1-4), 87-114. https://doi.org/10.1016/ S0378-4371(02)01383-3

22. Kumar, S., \& Deo, N. (2009). Multifractal properties of the Indian financial market. Physica A: Statistical Mechanics and its Applications, 388(8), 15931602. https://doi.org/10.1016/j. physa.2008.12.017

23. Mertzanis, C., \& Allam, N. (2018). Political Instability and Herding Behaviour: Evidence from Egypt's Stock Market. Journal of Emerging Market Finance, 17(1), 1-31. https://doi. org/10.1177/0972652717748087

24. Milos, L., Tiegan, C., Milos, M., Barna, F., \& Botoc, C. (2020). Multifractal Detrended
Fluctuation Analysis (MFDFA) of Stock Market Indexes. Empirical Evidence from Seven Central and Eastern European Markets. Sustainability, 12(535). https://doi.org/10.3390/ su12020535

25. Naresh, G., Ganesh, R., \& Thiyagarajan, S. (2019). An Assessment of the Mimicking Tendency of Investors in an Indian Benchmark Index. South Asain Journal of Management, 26(2), 135-160. Retrieved from https://www.proquest.com/ openview/7824e8ba1e2e84 d775a0968c6c83d367/1?pqorigsite $=$ gscholar $\& \mathrm{cbl}=46967$

26. Poon, S.-H., \& Granger, W. (2003). Forecasting Volatility in Financial Markets: A Review. Journal of Economic Literature, 40(2), 478-539. https://doi.org/10.1257/002205103765762743

27. Yim, K., Oh, G., \& Kim, S. (2014). An Analysis of the Financial Crisis in the KOSPI Market Using Hurst Exponents. Physica A: Statistical Mechanics and Its Applications, 410, 87114. https://doi.org/10.1016/j. physa.2014.05.033 